\title{
PRODUCCIÓN DE ELECTRICIDAD EMPLEANDO Acidithiobacillus ferrooxidans A PARTIR DE IONES TIOSULFATO Y FÉRRICO
}

\author{
Sandro Jibaja ${ }^{\mathrm{a}}$,Vanessa Oyola ${ }^{\mathrm{a}}$, Arturo Berastain ${ }^{\mathrm{a}}$, Daniel Ramos ${ }^{\mathrm{a}}$, Elisa Roncal ${ }^{\mathrm{a}}$, \\ Juan Carlos Medina ${ }^{\mathrm{a}}$, Graciela Untiveros ${ }^{\mathrm{a}}$, Patricia Sheen ${ }^{\mathrm{a}}$ y Jasmín Hurtado ${ }^{\mathrm{a}^{*}}$
}

\section{RESUMEN}

Los microorganismos acidófilos son predominantes en los ecosistemas de aguas ácidas de minas, encontrándose en abundancia la especie Acidithiobacillus ferrooxidans. El objetivo del estudio fue producir electricidad en Celdas de Combustible Microbianas (CCM) a partir del tiosulfato en el ánodo e ion férrico en el cátodo utilizando a la bacteria At. ferrooxidans LB151, la cual fue caracterizada morfológicamente y molecularmente. Las técnicas electroquímicas utilizadas fueron la cronoamperometría y la voltametría cíclica. La voltametría cíclica muestra picos de corriente de oxidación y reducción de los compuestos indicando que hay una interacción de la bacteria con la superficie del electrodo. La cronoamperometría mostró que la bacteria era capaz de producir electricidad al utilizar el tiosulfato con hierro. El voltaje generado por la CCM fue mayor que en la Celda de Combustible Control (CCC), produciendo una densidad de potencia promedio de $24,23 \mathrm{~mW} / \mathrm{m}^{2}$ en 4 horas mientras que la celda control produjo una densidad de potencia promedio de $3,41 \mathrm{~mW} / \mathrm{m}^{2}$ en el mismo tiempo. El total de energía generada por las bacterias fue $197,3 \mathrm{~mW} . \mathrm{H} / \mathrm{m} 2$ y los Coulombs

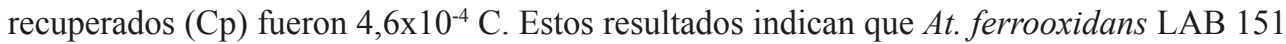
es capaz de producir electricidad a partir de iones tiosulfato y férrico como sustrato en Celdas de Combustible Microbianas.

Palabras clave: At. ferrooxidans, tiosulfato, férrico, celdas de combustible microbianas, electricidad

\section{PRODUCTION OF ELECTRICITY USING Acidithiobacillus ferrooxidans FROM THIOSULPHATE AND FERRIC IONS}

\begin{abstract}
Acidophilic microorganisms are predominant in the ecosystems of acid mine waters, being found in abundance the species Acidithiobacillus ferrooxidans. The objective of the study was to produce electricity in the Microbial Fuel Cells (MFC) from thiosulfate at the anode and ferric ion at the cathode using the bacteria At. ferrooxidans LB151, which was
\end{abstract}

\footnotetext{
* Facultad de Ciencias y Filosofía, , Universidad Peruana Cayetano Heredia,

* Lab. Biotecnologia Ambiental, LID, Av. Honorio Delgado 430, Lima-Perú

A.P, 4314, E- mail: jasmin.hurtado@upch.pe.
} 
characterized morphologically and molecularly. The electrochemical techniques used were chronoamperometry and cyclic voltammetry. The cyclic voltammetry show current peaks of oxidation and reduction of the compounds indicating that there is an interaction of the bacteria with the surface of the electrode. The voltage generated by the MFC is greater than the control cell, producing an average power density of $24.23 \mathrm{~mW} / \mathrm{m}^{2}$ in 4 hours while the control cell produced an average power density of $3.41 \mathrm{~mW} / \mathrm{m}^{2}$ in the same time. The total energy generated by the bacteria was $197.3 \mathrm{~mW} . \mathrm{H} / \mathrm{m}^{2}$ and the recovered Coulombs (Cp) were $4.6 \times 10^{-4} \mathrm{C}$. These results indicate that using ions of thiosulfate and ferric as a substrate in the Microbial Fuel Cells and inoculating with At. ferrooxidans LB151 electricity was produced.

Key words: At. ferrooxidans, thiosulfate, ferric, microbial fuel cells, electricity

\section{INTRODUCCIÓN}

El incremento de población en el planeta y la disminución de reservas de energía convencionales lleva a buscar nuevas fuentes de energía. Dentro de ellas se están trabajando las Celdas Microbianas de producción de Electricidad (CME). La CME es un dispositivo que produce energía eléctrica basada en las reacciones biológicas de óxido-reducción. Presenta dos cámaras separadas mediante una membrana semipermeable (que permite solo paso de protones): en una cámara se aloja el electrodo (ánodo) y en la otra cámara se coloca un segundo electrodo (cátodo). La CME puede emplear en el ánodo microorganismos electrógenos ${ }^{1}$ que convierten la energía almacenada en sustratos orgánicos e inorgánicos a energía eléctrica durante su respiración anaeróbica. Los microorganismos en el ánodo pueden transferir los electrones al electrodo directamente o a través de estructuras ${ }^{1}$. Muchos microorganismos pueden formar biofilms en los electrodos, pero se debe demostrar su capacidad de ceder o donar electrones ${ }^{1}$ para poder ser utilizados de manera eficiente.

El procesamiento de sulfuros puede liberar metales y compuestos reducidos de azufre tales como tiosulfato $\left(\mathrm{S}_{2} \mathrm{O}_{3}{ }^{2-}\right)$ y tetrationato $\left(\mathrm{S}_{4} \mathrm{O}_{6}{ }^{2-}\right)$ en las aguas ácidas que normalmente tienen además iones fierro y otros en solución a $\mathrm{pH}$ bajo. La mayoría de los estudios sobre CME son a condiciones de $\mathrm{pH}$ neutro con sustratos orgánicos tales como acetato, glucosa y materiales complejos $^{2}$. Los sustratos inorgánicos en celdas de combustible microbianas han sido poco estudiados, se han estudiado compuestos como azufre, sulfato y con tetrationato ${ }^{3,4}$.

El objetivo de este estudio fue examinar la capacidad de una cepa de Acidithiobacillus ferrooxidans de utilizar los iones tiosulfato como donador de electrones en el ánodo de una MFC, en condiciones acidas $(\mathrm{pH}<3)$ típicas de los efluentes de mina para producir electricidad. 


\section{PARTE EXPERIMENTAL}

\section{Microorganismo, medios de crecimiento e identificación molecular}

La cepa Acidithiobacillus ferrooxidans LB151 fue cultivada en el medio líquido Tk/Tio-Et ${ }^{5}$ a pH 3.5, en anaerobiosis e incubado a $28^{\circ} \mathrm{C}$ por un periodo de 7 a 30 días. El medio sólido $\mathrm{FeO}^{6}$ fue usado para caracterización de colonias.

La identificación molecular de At. ferrooxidans LB151 se realizó del ADN genómico obtenido de un cultivo de $50 \mathrm{~mL}$. Se centrifugó a $1000 \mathrm{rpm}$ por $2 \mathrm{~min}$ para descartar las sales y el sobrenadante fue centrifugado a $12500 \mathrm{rpm}$ por 20 minutos para obtener en el precipitado la suspensión bacteriana. El ADN fue extraído de la biomasa bacteriana mediante el método de fenol-cloroformo ${ }^{7}$. Una porción del gen 16S rRNA fue amplificado utilizando los primers $8 \mathrm{~F}$ y $1492 \mathrm{R}^{8}$. El secuenciamiento fue llevado a cabo por Macrogen $\mathrm{C}$ MD, USA (https:// dna.macrogen.com/eng/index.jsp). Los resultados obtenidos fueron evaluados por BLASTn (NCBI).

\section{Prueba en Celda Microbianas de producción de Electricidad (CME) y sustratos Construcción y operación de la CME}

Se utilizó una celda microbiana de producción de electricidad (CME) de material acrílico teniendo $10 \mathrm{~mL}$ de volumen útil de trabajo tanto para el anolito como para el catolito. La celda constaba de dos compartimientos, un ánodo y un cátodo, separados por una membrana intercambiadora de protones (Nafion 117). La activación de la membrana fue realizada por inmersión secuencial, primero en agua destilada durante 1 hora a $80^{\circ} \mathrm{C}$, segundo en una solución al $3 \%$ de $\mathrm{H} 2 \mathrm{O} 2$ por 1 hora a $80{ }^{\circ} \mathrm{C}$ y tercero en $\mathrm{H} 2 \mathrm{SO} 4(0.5 \mathrm{M})$ por 1 hora a $80{ }^{\circ} \mathrm{C}$.

El inóculo del cultivo de Acidithiobacillus ferrooxidans LB151 fue obtenido luego de la centrifugación de $5 \mathrm{~mL}$ de cultivo a $5000 \mathrm{rpm}$ por 5 minutos. El sobrenadante fue La suspensión bacteriana fue lavada tres veces con agua ácida estéril ( $\mathrm{pH} 3,5)$. Finalmente, las bacterias fueron resuspendidas en medio a emplear en la celda anódica.

En el compartimiento del ánodo se utilizó una solución de tiosulfato como anolito a pH 3,5 con la siguiente composición (g/L): $5 \mathrm{~g} \mathrm{Na}_{2} \mathrm{~S}_{2} \mathrm{O}_{3} .5 \mathrm{H}_{2} \mathrm{O} ; 0,57 \mathrm{~g}\left(\mathrm{NH}_{4}\right)_{2} \mathrm{SO}_{4} ; 0,535 \mathrm{~g} \mathrm{MgSO}_{4} .7 \mathrm{H}_{2} \mathrm{O}$; $0,655 \mathrm{~g} \mathrm{KH}_{2} \mathrm{PO}_{4} ; 1,25 \mathrm{ml}$ elementos traza (1L contiene $10 \mathrm{mg}$ de $\mathrm{ZnSO}_{4} .7 \mathrm{H}_{2} \mathrm{O} ; \mathrm{CuSO}_{4} .7 \mathrm{H}_{2} \mathrm{O}$; $\mathrm{MnSO}_{4} \cdot \mathrm{H}_{2} \mathrm{O} ; \mathrm{H}_{3} \mathrm{BO}_{3} ; \mathrm{Na}_{2} \mathrm{MoO}_{4} \cdot 2 \mathrm{H}_{2} \mathrm{O} ; \mathrm{NiSO}_{4} \cdot 6 \mathrm{H}_{2} \mathrm{O} ; \mathrm{CoSO}_{4} \cdot 7 \mathrm{H}_{2} \mathrm{O} ; \mathrm{Cr}\left(\mathrm{NO}_{3}\right)_{3} \cdot 9 \mathrm{H}_{2} \mathrm{O} ; \mathrm{SeO}_{2}$; $\mathrm{V}_{2} \mathrm{O}_{5}$ ), $\mathrm{y}$ en el compartimiento del cátodo se utilizó una solución férrica a $\mathrm{pH} 3.6$ con la siguiente composición: 6,92g Fe+3, 1,33g (NH4)2SO4; 0,53g MgSO4.7H2O; 0,25g TSB y $1 \mathrm{ml}$ elementos traza. Ambos compartimientos presentaban electrodos de fieltro de grafito de 1 x $1 \mathrm{~cm}$ teniendo un área de $1 \mathrm{~cm} 2$, los cuales fueron limpiados con H2SO4 (2N) y autoclavados a $120^{\circ} \mathrm{C}$ a $1 \mathrm{~atm}$ por 30 minutos para después ser atravesados con un alambre de platino y conectados a una resistencia externa de 5,6 K $\Omega$.

En el ánodo del CME se colocó el inoculo y medio mientras que en la celda de combustible control (CCC) se colocó solo medio. En las dos celdas, el compartimiento del ánodo fue burbujeado durante 10 minutos con una mezcla de $\mathrm{N}_{2}$ y $\mathrm{CO}_{2}$ ( $80 \%$ y $20 \%$, respectivamente) 
para generar anaerobiosis y fue sellado manualmente con silicona y soldimix. El catolito fue mantenido en condiciones aeróbicas. Ambas celdas fueron monitoreadas periódicamente utilizando un multímetro Fluke 289 (Fluke Corporation, The Netherlands) conectado a la resistencia del circuito eléctrico durante 164 horas.

\section{Pruebas en celda electrolítica (CE) y sustratos}

La caracterización electroquímica del cultivo de Acidithiobacillus ferrooxidans LB151 fue determinada por medio de dos técnicas electroquímicas: 1. Voltametría cíclica, para caracterizar la actividad sobre el sustrato. 2 Cronoamperometría, para monitorear la producción de electricidad.

La voltametría cíclica fue realizada en una celda electrolítica estéril con una configuración de tres electrodos; un electrodo de referencia de $\mathrm{Ag} / \mathrm{AgCl}$, como electrodo de trabajo y contra electrodo se usó grafito poroso con un área de $1 \mathrm{~cm}^{2}$, agregándole $36 \mathrm{ml}$ del sustrato en su interior y $4 \mathrm{ml}$ del inóculo preparado de At. ferrooxidans LB151. Se trabajó en atmósfera controlada con una mezcla de $\mathrm{N}_{2}$ y $\mathrm{CO}_{2}(80 \%$ y $20 \%$, respectivamente) durante 10 minutos y sellada con plastifilm.

Se utilizó los siguientes parámetros para voltametría cíclica; se aplicó un barrido de potencia $-1 \mathrm{~V}$ a $-1 \mathrm{~V}$ bajo una velocidad de barrido de $100 \mathrm{mV} / \mathrm{s}$ durante 7 ciclos para estabilización del sistema. Las medidas fueron hechas cada hora por un lapso de 7 horas durante 3 días. Además, se realizó una muestra control con $40 \mathrm{~mL}$ de sustrato sin inoculo bajo las mismas condiciones de la voltametría cíclica. Como sistema estándar utilizamos la especie oxidoreductora de ferri/ferro cianuro de potasio $0,1 \mathrm{mM}$ en la misma ventana de potencial $-1 \mathrm{~V}$ hacia $-1 \mathrm{~V}$ con una velocidad de barrido de $100 \mathrm{mV} / \mathrm{s}$ enfrentado a un electrodo de referencia $\mathrm{Ag} / \mathrm{AgCl}$.

La cronoamperometría fue realizada en una celda electrolítica estéril con la configuración de tres electrodos colocando $36 \mathrm{ml}$ del sustrato y $4 \mathrm{ml}$ del inóculo preparado de At. ferrooxidans LB151 en su interior y siendo burbujeada con la mezcla de $\mathrm{N}_{2}$ y CO $\mathrm{CO}_{2}(80 \%$ y $20 \%$, respectivamente) durante 10 minutos y sellada con plastifilm. Esta celda se corrió en circuito cerrado a $440 \mathrm{mV}$ con el potenciostato Model 273A Potentiostat/Galvanostat Princeton Applied Research, durante 12 horas. Asimismo, se corrió un control que contenía solo $40 \mathrm{~mL}$ del medio, usando las condiciones descritas.

El sustrato empleado en las dos pruebas tuvo la siguiente composición por litro: $5 \mathrm{~g}$ $\mathrm{Na}_{2} \mathrm{~S}_{2} \mathrm{O}_{3} .5 \mathrm{H} 2 \mathrm{O}, 6,92 \mathrm{~g} \mathrm{Fe}+3,786 \mathrm{~g}\left(\mathrm{NH}_{4}\right)_{2} \mathrm{SO}_{4}, 0,958 \mathrm{~g} \mathrm{MgSO} \mathrm{Mg}_{4} .7 \mathrm{H}_{2} \mathrm{O}, 0,524 \mathrm{~g} \mathrm{KH} \mathrm{KO}_{4}$, $0,25 \mathrm{~g}$ Trypticase Soy Broth (Difco, Detroit, MI) y $2 \mathrm{ml}$ elementos traza (1L contiene $10 \mathrm{mg}$ de $\mathrm{ZnSO}_{4} \cdot 7 \mathrm{H}_{2} \mathrm{O}, \mathrm{CuSO}_{4} \cdot 7 \mathrm{H}_{2} \mathrm{O}, \mathrm{MnSO}_{4} \cdot \mathrm{H}_{2} \mathrm{O}, \mathrm{H}_{3} \mathrm{BO}_{3}, \mathrm{Na}_{2} \mathrm{MoO}_{4} \cdot 2 \mathrm{H}_{2} \mathrm{O}, \mathrm{NiSO}_{4} \cdot 6 \mathrm{H}_{2} \mathrm{O}$, $\left.\mathrm{CoSO}_{4} \cdot 7 \mathrm{H}_{2} \mathrm{O}, \mathrm{Cr}\left(\mathrm{NO}_{3}\right)_{3} \cdot 9 \mathrm{H}_{2} \mathrm{O}, \mathrm{SeO} 2, \mathrm{~V} 2 \mathrm{O} 5\right)$. Se trabajó a condiciones anaeróbicas, a $\mathrm{pH}$ de 3,5 . 


\section{Monitoreo químico de la CME y CE}

$\mathrm{El}$ análisis cualitativo $\left(\mathrm{S}_{2} \mathrm{O}_{3}^{-2}, \mathrm{SO} 3-2, \mathrm{SO} 4-2, \mathrm{Fe}+3, \mathrm{Fe}+2\right)$ se realizó según la metodología descrita por Alexéiev V. y Vogel $\mathrm{A}^{9}$. Esto se realizó con el fin de conocer los cambios químicos de los iones tiosulfato y férrico. La determinación de sulfatos se realizó con el fin de cuantificar el cambio químico del ion tiosulfato según el método $4500 \mathrm{SO}_{4}^{-2}-\mathrm{C}_{\text {descrito }}$ en Standard Methods for the Examination of Water and Wastewater ${ }^{10}$.

\section{Monitoreo electroquímico y análisis de la producción de energía en CME}

El monitoreo se llevó a cabo mediante mediciones de voltaje en la CME utilizando un multímetro marca Fluke 289. Para obtener los datos de corriente se fijó una resistencia para el circuito. La corriente (I) en amperios se obtuvo como $\mathrm{I}=\mathrm{V} \times \mathrm{R}^{-1}=\mathrm{Q} \times \mathrm{t}^{-1}$, donde $\mathrm{V}$ es el voltaje (voltios), Q es la carga (coulombs) y t es el tiempo (segundos). La potencia (P; vatios) de la celda se midió como $\mathrm{P}=\mathrm{I} \times \mathrm{V}$.

Para realizar el cálculo del voltaje generado por cada celda se aplicó la siguiente resta: Voltaje Generado $=$ Voltaje de la Celda Inoculada - Voltaje de la Celda Control

La densidad de potencia (DP) fue calculado con la siguiente ecuación ${ }^{11}$ :

$$
D P=\frac{\left(V_{-} G e n\right)^{2}}{R * A}
$$

Donde:

$\mathrm{DP}=$ Densidad de potencia $\left(\mathrm{mW} / \mathrm{m}^{2}\right)$

V_Gen $=$ Voltaje generado en $(\mathrm{mV})$

$\mathrm{R}=$ Resistencia externa (Ohmios), siendo la escogida 5,6 KOhms

$\mathrm{A}=$ Área del electrodo $\left(\mathrm{m}^{2}\right)$, teniendo cada uno de estos $1 \mathrm{~cm}^{2}$

La energía producida por la CME se calculó utilizando el programa MatLab 8.0 (The MathWorks, Inc., Natick, Massachusetts, United States), el cual gráfico la curva de la densidad de potencia $\left(\mathrm{mW} / \mathrm{m}^{2}\right)$ versus el tiempo $(\mathrm{H})$ por cada CME. El programa calculó el área bajo la curva de la gráfica antes mencionada con un procedimiento que convirtió las secciones entre puntos en trapezoides. Esto nos dio como resultado el total de energía generada ${ }^{12}$.

El total de Coulombs recuperados $(\mathrm{Cp})$ de la $\mathrm{CME}$ se determinó de la siguiente manera ${ }^{11}$ : el total de energía generada por las bacterias, se igualó matemáticamente a I ${ }^{2}$.R/A (Densidad de Potencia) y se determinó la intensidad de corriente en función del tiempo. Teniendo en cuenta que $\mathrm{C}=\mathrm{I} . \mathrm{t} ; 1 \mathrm{~W}=\mathrm{J} / \mathrm{s} ; 1 \mathrm{~J}=\mathrm{kg} \cdot \mathrm{m}^{2} / \mathrm{s}^{2} ; \Omega=\mathrm{kg} \cdot \mathrm{m}^{2} / \mathrm{A}^{2}$. $\mathrm{s} 3 ; \mathrm{A}=10^{-4} \mathrm{~m}^{2}$ y R $=5,6 \times 10^{3} \Omega$ para las conversiones respectivas.

Donde:

I: Intensidad de corriente (A),

A: Área superficial del electrodo (m2),

R: Resistencia $(\Omega)$, C: Coulombs (A.s),

W: Potencia (Watts),

J: Joule 


\section{Monitoreo electroquímico en celda electrolítica de Acidithiobacillus ferrooxidans}

Los datos de la voltametría y cronoamperometría fueron tabulados en el software Origin Pro 2017 (Origin Lab. Corporation, Massachusets). En la voltametría cíclica se ubicaron los picos de corriente de oxidación y reducción del sustrato. En la cronoamperometría se realizó un análisis cualitativo de la producción de corriente en un periodo de 12 horas.

\section{RESULTADOS Y DISCUSIÓN}

\section{Identificación fisiológica y molecular de las bacterias empleadas}

La cepa de Acidithiobacillus ferrooxidans LB151 creció en el medio líquido en anaerobiosis. En el medio sólido $\mathrm{FeO}$ presentó colonias de color anaranjado con forma irregular, borde irregular, elevación plana y superficie rugosa (figura 1) y fue identificada molecularmente como Acidithiobacillus ferrooxidans (NCBI secuencia de referencia: NR_074193.1) con un $95 \%$ de identidad.

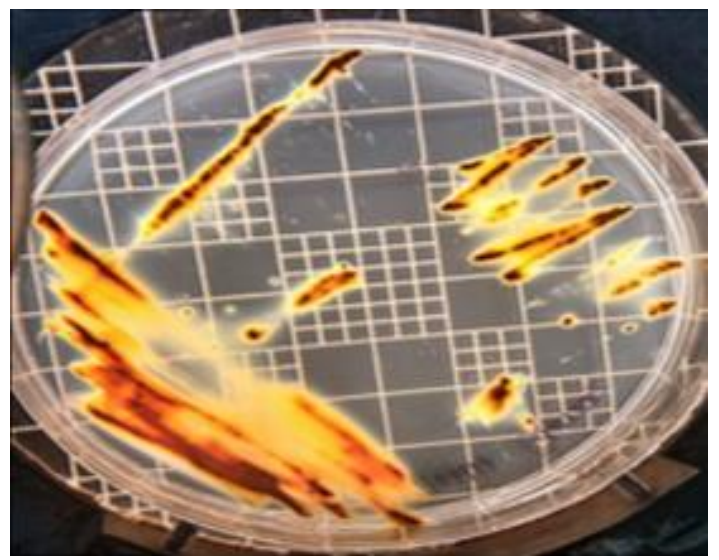

Figura 1. Colonias de Acidithiobacillus ferrooxidans LB151 en el medio sólido FeO

\section{Monitoreo electroquímico y análisis de la producción de electricidad en celda microbiana}

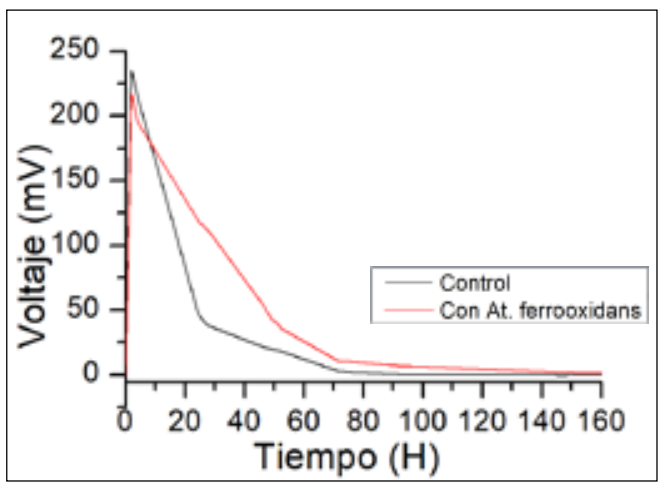

Figura 2. Voltaje total de la CME y de la celda CC 
La celda con inóculo de At. ferrooxidans LB151 y la celda sin inóculo fueron monitoreadas por un periodo de 160 horas como puede observarse en la figura 2. Se observa que a partir de las 20 horas el voltaje generado por la $\mathrm{CME}$ es mayor que la celda control, produciendo una densidad de potencia promedio de $24,23 \mathrm{~mW} / \mathrm{m}^{2}$ en 4 horas mientras que la celda control produjo una densidad de potencia promedio de $3,41 \mathrm{~mW} / \mathrm{m}^{2}$ en el mismo tiempo. El total de energía generada por las bacterias fue $197,3 \mathrm{~mW} . \mathrm{H} / \mathrm{m}^{2}$ y los Coulombs recuperados (Cp) fueron $4,6 \times 10^{-4} \mathrm{C}$.

La densidad de potencia difiere a la publicada por Ni y colaboradores ${ }^{4}$ que con microorganismos acidófilos produjo una densidad de potencia de $2,5 \mathrm{~mW} / \mathrm{m}^{2}$ a partir de aguas de minas suplementadas con tetrationato y del trabajo de Sulonen y colaboradores ${ }^{3}$ donde utiliza un cultivo acidófilo (En 1) que produce una densidad promedio de $0,51 \mathrm{~mW} / \mathrm{m}^{2}$ teniendo como anolito una mezcla del medio suplementados con tetrationato. Sin embargo, la condición de los tres trabajos es distinta lo cual puede aumentar o disminuir la densidad de potencia de las celdas.

\section{Monitoreo electroquímico en celda electrolítica de Acidithiobacillus ferrooxidans}

La voltametría cíclica del sustrato sin inóculo bacteriano permitió la observación de picos poco definidos de reducción del tiosulfato (figura 2) o del fierro en el primer día, posteriormente empieza a definirse picos de reducción de tiosulfato a $495 \mathrm{mV}$ (día 3).

Cuando se agregó el inóculo al cultivo, observamos en el primer día picos poco definidos como en el control, pero a partir de las 5 horas se observó reducción de tiosulfato, la cual se incrementó considerablemente hasta el día 2. Por el contrario, en el tercer día, se observó la disminución de dicho pico relacionado con el desgaste del medio por actividad bacteriana (figura 3), además se evidenció la formación de un pico adicional relacionado a la oxidación de fierro $190 \mathrm{mV}$, esto es debido a la producción de intermediarios producto de la metabolismo bacteriano $^{13}$.

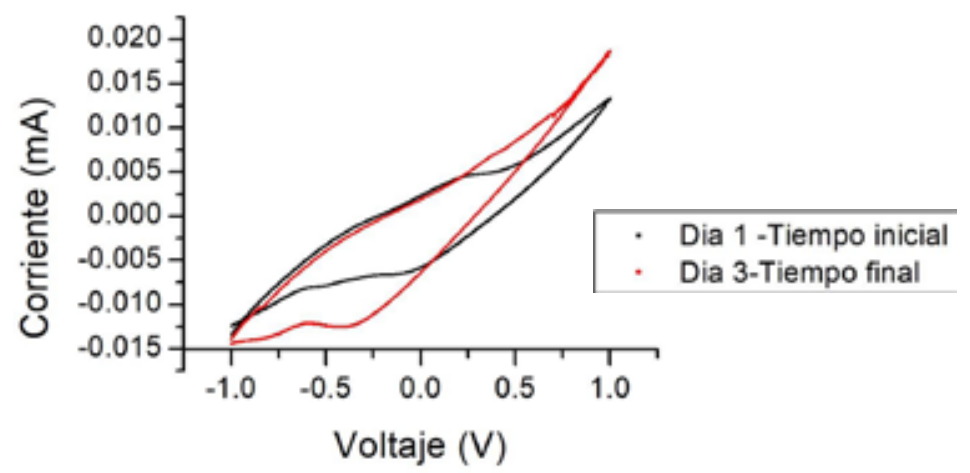

Figura 3. Voltametría Cíclica del sustrato sin inoculación 


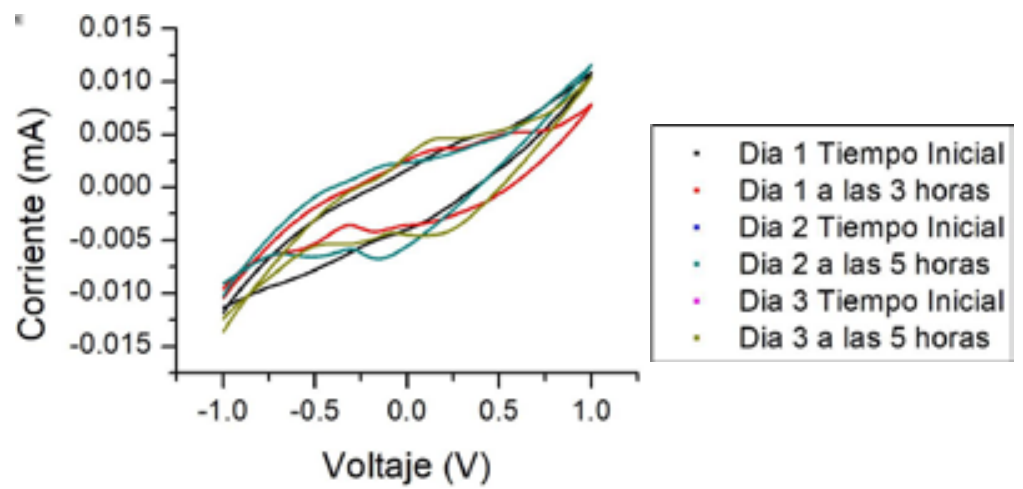

Figura 4. Voltametría Cíclica del sustrato inoculado con el cultivo de At. ferrooxidans (cepa 151).

En la figura 4 se observa los resultados de la cronoamperometría al sustrato, la que se evaluó en ausencia de bacterias y en presencia de At. ferrooxidans. La cronoamperometría en ausencia de bacterias evidencia una señal constante por debajo de cero demostrando perdida de corriente del equipo. Por otro lado, en presencia de bacterias se evidencia una producción de corriente con un máximo 5,84 mA a partir de los primeros 30 minutos, la cual se mantiene constante por las $12 \mathrm{~h}$ que duró el experimento.

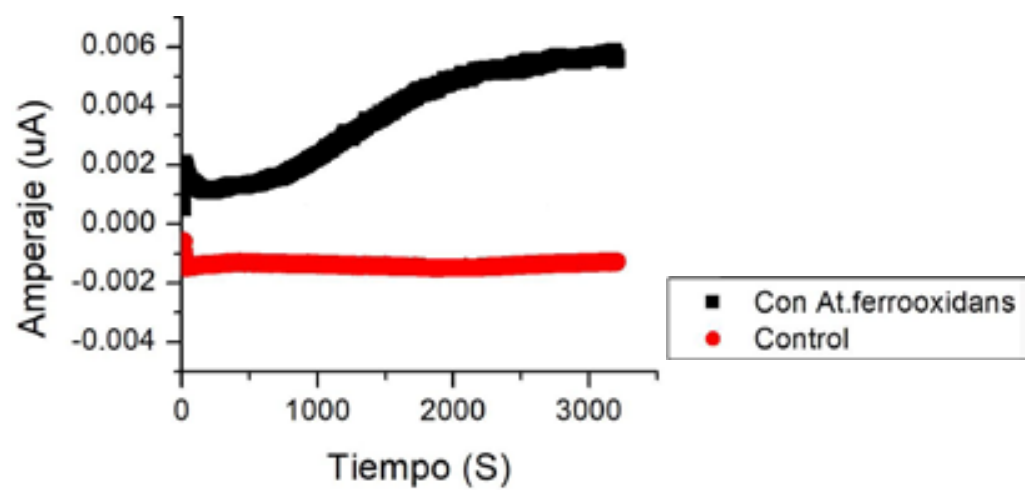

Figura 5. Cronoamperometría al medio tiosulfato y solución férrica en ausencia y presencia de bacterias.

\section{Monitoreo químico en la CME y CE}

El análisis cualitativo de la presencia de iones en la celda electrolítica antes y finalizado el experimento de la cronoamperometría se muestra en la tabla 1. Este análisis mostró que la única diferencia fue la reducción del férrico por la acción bacteriana. 
Tabla 1. Análisis cualitativo de la cronoamperometría

\begin{tabular}{cccc}
\hline Iones & Inicial & $\begin{array}{c}\text { Final Crono } \\
\text { con bacterias }\end{array}$ & $\begin{array}{c}\text { Final Crono } \\
\text { control }\end{array}$ \\
\hline $\mathrm{S}_{2} \mathrm{O}_{3}^{-2}$ & + & - & - \\
$\mathrm{SO}_{4}^{-2}$ & + & + & + \\
$\mathrm{SO}_{3}^{-2}$ & - & - & - \\
$\mathrm{Fe}^{+3}$ & + & - & + \\
$\mathrm{Fe}^{+2}$ & + & + & + \\
\hline
\end{tabular}

La determinación del contenido de sulfatos mostró una mayor producción del mismo en la celda electrolítica con bacterias $(4,56 \mathrm{~g} / \mathrm{l})$ a diferencia del control $(3,99 \mathrm{~g} / \mathrm{l})$. Estos resultados concuerdan con lo observado en la voltametría cíclica donde se observa mayor concentración en el pico de $495 \mathrm{mV}$ en la presencia de bacterias.

La reducción del ion férrico a ferroso se verificó a partir del análisis cualitativo en la cronoamperometría con bacterias, lo cual es correcto ya que A. ferrooxidans es capaz de reducir el ion férrico ${ }^{13}$. Con respecto al control, se observó presencia de ambos iones $\mathrm{Fe}^{3+}$ y $\mathrm{Fe}^{2+}$ al final del experimento, resultado que indicaría la posible reducción por el voltaje aplicado en la celda electrolítica, tal como fue demostrado en las pruebas de voltametría cíclica previas.

Las pruebas cualitativas en la celda de combustible microbiana y celda control evidenciaron la desaparición de tiosulfato, ausencia de sulfitos y presencia de sulfatos en el ánodo, y en el cátodo, la aparición de iones ferroso; sin embargo, mostró aún presencia de iones férrico. La determinación de sulfatos como prueba cuantitativa arrojó un valor menor en la celda de combustible microbiana $(4,28 \mathrm{~g} / \mathrm{l})$ con respecto a la celda de combustible control $(4,90)$.

Esta mayor producción de sulfatos en la celda de combustible control a partir de tiosulfato ha sido confirmada por Starkey14 que determinó que en cultivos batch (que es el caso de la cámara anódica) el azufre y el tiosulfato llegan a oxidarse completamente a sulfato por Thiobacillus thiooxidans.

En las cámaras catódicas se da la reducción de hierro (III) a hierro (II), al tratarse de condiciones ácidas, lo cual facilita su disolución. Sin embargo, al determinarse cualitativamente la presencia de ambos iones, $\mathrm{Fe}^{3+}$ y $\mathrm{Fe}^{2+}$, se podría inferir que ocurrió reoxidacion de hierro (II) a hierro (III), puesto que Acidithiobacillus ferrooxidans tiene la peculiaridad de oxidar iones $\mathrm{Fe}^{2+}$ en condiciones ácidas y aeróbicas (13). $\mathrm{El} \mathrm{O}_{2}$ y Fe ${ }^{3+}$, entre otros, son los aceptores terminales de electrones que Acidithiobacillus ferrooxidans es capaz de usar en su cadena respiratoria de electrones para sostener su crecimiento bacteriano ${ }^{15}$. 


\section{CONCLUSIONES}

En este estudio se ha demostrado que la cepa Acidithiobacillus ferrooxidans LB151 es capaz de transferir electrones y generar bioelectricidad en condiciones ácidas en celdas microbianas con ion tiosulfato en el ánodo y ion férrico en el cátodo. Asimismo, es capaz de generar electricidad en celdas electrolíticas a partir de tiosulfato y sulfato férrico. Se debería continuar estudiando el efecto electroquímico de los microorganismos en los procesos biohidrometalúrgicos.

\section{AGRADECIMIENTO}

Este trabajo ha sido financiado por el FONDECYT (CONCYTEC) bajo el contrato 113-2015. Asimismo, los autores agradecen la participación de Jacqueline Begazo en la estandarización de la celda microbiana y del Dr. Luis Ortiz Frade de CIDETEQ en el desarrollo de las pruebas iniciales.

\section{REFERENCIAS BIBLIOGRÁFICAS}

1. Lovley DR. The microbe electric: conversion of organic matter to electricity. Curr Opin Biotechnol. 2008; 19:564-571.

2. Pant D, Van Bogaert G, Diels L, Vanbroekhoven K. A review of the substrates used in microbial fuel cells (MFC) for sustainable energy production. Bioresour Technol. 2010; 101(6): 1533-1543.

3. Sulonen M, Kokko M, Lakaniemi A, Puhakka J. Electricity generation from tetrathionate in microbial fuel cells by acidophiles. J Hazard Mater. 2015; 284: 182-189.

4. Ni G, Christel S, Roman P, Wong Z, Bijmans M, Dopson M. Electricity generation from an inorganic sulfur compound containing mining wastewater by acidophilic microorganisms. Res Microbiol. 2016; 167(7): 568-575.

5. Tuovinen $0 \mathrm{H}$, Kelly DP. Studies on the growth of Thiobacillus ferrooxidans. I. Use of membrane filters and ferrous iron agar to determine viable numbers and comparison with "14CO2-fization and iron oxidation as measures of growth. Arch Mikrobiol. 1973; 88: 285-298.

6. Johnson DB. Selective solid media for isolating and enumerating acidophilic bacteria. J Microbiol Methods. 1995; 23:205- 18.

7. Goldenberger D, Perschil I, Ritzler M, Altwegg M. A simple “universal” DNA extraction procedure using SDS and proteinase $\mathrm{K}$ is compatible with direct PCR amplification. PCR Methods Appl. 1995; 4(6):368-370.

8. Quintana M. Identificación molecular de microorganismos biooxidantes en drenajes ácidos de mina (DAM). [Tesis para optar el grado de magister en bioquímica y biología molecular]. Lima: Universidad Peruana Cayetano Heredia; 2011.

9. Vogel A. Química Analítica Cualitativa. Sexta edición. Buenos Aires: Kapelusz S.A.; 1983. 
10. American Public Health Association. Standard Methods for the Examination of Water and Wastewater. 20th Edition. Washington: American Water Works Association,US; 1998.

11. Logan BE, Hamelers B, Rozendal R, Schröder U, Keller J, Freguia S, et al. Microbial fuel cells: methodology and technology. Environ Sci Technol. 2016; 40(17): 5181-5192.

12. Pistonesi C, Haure J, D'Elmar R. Energía a partir de las aguas residuales. Buenos Aires: Editorial de la Universidad Tecnológica Nacional - edUTecNe; 2010.

13. Saavedra Salas IM. Diseño de una Celda de Combustible Microbiológica con Uso de Bacterias Oxidantes de Azufre y Hierro. [Tesis de Pregrado]. Santiago de Chile: Universidad de Chile; 2012.

14. Starkey R. Products of the oxidation of thiosulfate by bacteria in mineral media. J Gen Physiol. 1935; 18(3): 325 - 349 .

15. Pronk J, Meulenberg R, Bos P, Kuenen J. Oxidation of reduced inorganic sulphur compounds by acidophilic thiobacillius. FEMS Microbiol Rev. 1990; 75: 293-306. 